\title{
Inhibition of basal JNK activity by small interfering RNAs enhances cisplatin sensitivity and decreases DNA repair in T98G glioblastoma cells
}

\author{
EDUARDO PARRA $^{1}$, LUIS GUTIÉRREZ ${ }^{2}$ and JORGE FERREIRA ${ }^{3}$ \\ ${ }^{1}$ Laboratory of Experimental Biomedicine, University of Tarapaca, Campus Esmeralda, Iquique; \\ ${ }^{2}$ Faculty of Sciences, Arturo Prat University, Iquique; ${ }^{3}$ Programme of Molecular and Clinical Pharmacology, \\ ICBM, Medical Faculty, University of Chile, Independencia, Santiago, Chile
}

Received May 16, 2014; Accepted September 22, 2014

DOI: $10.3892 /$ or.2014.3570

\begin{abstract}
Inhibition of basal Jun kinase (JNK) activity by small interfering RNAs (siRNAs) enhances cisplatin sensitivity and decreases DNA repair in T98G glioblastoma cells. Although the JNK pathway has been extensively studied in recent years, little is known concerning the signaling pathways that control their expression in glioma cells. The aim of the present study was to assess the role of c-Jun- $\mathrm{NH}_{2}$-terminal kinases (JNKs) in the regulation of T98G glioblastoma cells treated with cisplatin in the presence or absence of siRNAs against JNK1 and JNK2. Addition of either small interfering JNK1-siRNA or JNK2-siRNA induced decreased DNA repair and sensitized the T98G glioblastoma cells to the DNA damaging drug cisplatin (cis-diamminedichloroplatinum). This effect was associated with reduced cell survival and loss of anchorage-independent colony formation. The results indicate that effective inhibition of the JNK pathway significantly sensitizes glioblastoma cells to cisplatin, a compound of proven clinical value whose spectrum of application is limited by resistance phenomena.
\end{abstract}

\section{Introduction}

We and other researchers have shown that the Jun kinase (JNK) mediates transformation (1-4) and is activated by genotoxic stress. Inhibition of this pathway is postulated to i) inhibit the JNK contribution to the transformed phenotype; and ii) to inhibit DNA repair and synthesis thereby sensitizing tumor cells to cisplatin (P1atinol) and other DNA-damaging chemotherapeutic agents. Cisplatin is a well-studied chemotherapeutic agent that acts through DNA damage (5). It is widely used (particularly for ovarian, bladder and testicular

Correspondence to: Dr Eduardo Parra, Laboratory of Experimental Biomedicine, University of Tarapaca, Campus Esmeralda, Avenida Luis Emilio Recabarren 2477, Iquique, Chile

E-mail: eparra@uta.cl

Key words: JNK, siRNA, T98G cells, cisplatin carcinomas), yet, is ineffective in breast carcinoma (6). However, drug resistance remains one of the biggest obstacles to successful treatment of cancer and is believed to be the primary reason for the treatment failure encountered in approximately half of all cancers. Brain tumors with wild-type (wt) or mutant p53 status may respond differently to radiation therapy. Actually, the p53 gene is found to be mutated in more than $40 \%$ of gliomas (7) and it is believed that restoration of p53 function would enhance the response to chemotherapeutic treatments $(6,8)$. The mechanism of resistance to therapeutic drugs, most of which lead directly or indirectly to DNA damage, is closely linked to the mechanisms of cancer, which we now know to involve in part genetic changes that alter the cellular response to DNA damage. Thus, many of the genetic changes, including loss of $\mathrm{p} 53$, that affect the response to therapy may affect tumor progression as well. Another important cellular pathway, also triggered in response to DNA damage is the Jun kinase/stress-activated protein kinase pathway (JNK/SAPK), one of several distinct mitogen-activated protein kinase (MAPK) pathways involved in signal transduction. JNK phosphorylates c-Jun, thereby enhancing the transcriptional activity of c-Jun. The JNK/SAPK pathway is induced by oncogene expression (9-12) and is essential for transformation of rat embryo fibroblasts $(13,14)$. JNK activity is strongly induced in response to a variety of DNA damaging treatments such as UV irradiation (15), cisplatin (16-19) and camptothecin (4,20), and as we have shown, appears to promote resistance of tumor cells to cisplatin through a mechanism involving increased DNA repair. We examined the role of the JNK pathway following treatment with cisplatin, in T98G glioblastoma cells (which express mutant p53) transfected with JNK1- and JNK2small interfering RNAs (siRNAs). Therefore, the JNK/SAPK pathway plays a p53-independent role in resistance to DNA damaging agents in these cells, yet not to agents that do not damage DNA (21). In each case the promoter region contains one or more AP-1 or ATF2/CREB regulatory sequences. Thus, several of the genes known to be involved in cisplatin-DNA adduct repair may be upregulated upon activation of the JNK pathway following damage to DNA by cisplatin, and the downregulation of one or more of them in JNK-siRNA-treated cells could account for the therapy sensitization effect we observed. 
The activation of JNK and loss of p53 may represent independent mechanisms by which tumor cells undergo progression to accommodate genome instability and ensure survival while sustaining potentially lethal genome destabilizing events. By promoting DNA repair, the JNK pathway may help to limit genome instability and the associated DNA damage to levels compatible with survival limiting genome instability. In the present study, we investigated the possibility of sensitization of glioma cells to cisplatin by abrogation of Jun-N-terminal kinase activity. We compared the response of basal JNK protein expression in untreated T98G cells and in cells treated with JNK1-siRNA, JNK2-siRNA alone or in combination with cisplatin. We found that disruption of either JNK1 or JNK2 by siRNAs sensitized T98G cells to cisplatin thereby markedly decreasing the viability of the cells.

\section{Materials and methods}

Cell culture. The T98G brain tumor cell line, established from human glioblastoma, was obtained from the American Type Culture Collection (ATCC; Manassas, VA, USA). The cells were cultured in Dulbecco's modified Eagle's medium (DMEM) (Invitrogen, Carlsbad, CA, USA) supplemented with $10 \%$ fetal bovine serum (FBS), $1 \mathrm{mM}$ sodium pyruvate, $100 \mathrm{Um} / 1$ penicillin $\mathrm{G}, 100 \mu \mathrm{g} / \mathrm{ml}, 1$ streptomycin, $2 \mathrm{mM}$ glutamine, $1 \mathrm{mM}$ MEM non-essential amino acids and $50 \mu \mathrm{M}$ 2-mercaptoethanol in a $5 \% \mathrm{CO}_{2}$ incubator at $37^{\circ} \mathrm{C}$. The cells were dissociated using $0.25 \%$ trypsin and $0.53 \mathrm{mM}$ EDTA solution and subcultured once in 3-5 days.

Reagents. Tris-borate-EDTA and acrylamide:bisacrylamide (29:1) were obtained from Bio-Rad (Richmond, CA, USA). Lipofectamine was obtained from Life Technologies, Inc., USA. Complete Mini EDTA-free protease inhibitor cocktail tablets and Annexin V-Fluos were purchased from Roche Diagnostics GmbH (Mannheim, Germany). Phorbol 12-myristate-13-acetate (TPA) and TNF- $\alpha$ were purchased from Stratagene Inc. (La Jolla, CA, USA). Antibodies JNK (FL) (sc-571). JNK-1 (C-17) (sc-474), JNK2 (N18) (sc-827) and $\beta$-actin (sc-1616) were used at a concentration of 0.07 and $0.1 \mathrm{mg} / \mathrm{ml}$, respectively (in a total volume of $12 \mathrm{ml}$ ), and were purchased from Santa Cruz Biotechnology, Inc. (Santa Cruz, CA, USA).

siRNA transfection. T98G glioblastoma cells were cultured to $60-80 \%$ confluency on 6-well plates. The cells were incubated with $60 \mathrm{nmol} / 1 \mathrm{siRNAs}$ (Santa Cruz) targeting JNK1 (sc-29380), JNK2 (sc-39101) or control 'scrambled' siRNA (sc-37007) and $6 \mu \mathrm{l}$ siRNA transfection reagent, according to the manufacturer's recommendation (Santa Cruz) in $1 \mathrm{ml}$ serum-free medium (MEM) at $37^{\circ} \mathrm{C}$ for $6 \mathrm{~h}$. After transfection, cells were cultured in complete medium for $42 \mathrm{~h}$ or until being used. The siRNAs were purchased from Santa Cruz Biotechnology, Inc.

Western immunoblot analysis. After reaching 70-80\% confluency, T98G cells were starved overnight with serum-free medium, and then treated at the indicated concentrations and time periods with the different drugs in the absence of serum. Forty-eight hours after transfection, cells were collected and washed twice by cold PBS, and each well was treated with $50 \mathrm{ml}$ lysis buffer $(2 \mathrm{mmol} / 1 \mathrm{Tris}-\mathrm{HCl} \mathrm{pH} \mathrm{7.4,} 50 \mathrm{mmol} / \mathrm{l}$ $\mathrm{NaCl}, 25 \mathrm{mmol} / \mathrm{l}$ EDTA, $50 \mathrm{mmol} / \mathrm{l} \mathrm{NaF}, 1.5 \mathrm{mmol} / 1 \mathrm{Na}_{3} \mathrm{VO}_{4}$, $1 \%$ Triton X-100, $0.1 \%$ SDS, supplemented with protease inhibitors $1 \mathrm{mmol} / 1$ phenylmethylsulfonyl fluoride, $10 \mathrm{mg} / \mathrm{l}$ pepstatin, $10 \mathrm{mg} / \mathrm{l}$ aprotinin and $5 \mathrm{mg} / \mathrm{l}$ leupeptin) (all from Sigma). Protein concentrations were determined using the Bradford protein assay. Equal amounts of protein $(40 \mathrm{mg})$ were separated on a $15 \%$ SDS polyacrylamide gel and transferred to a nitrocellulose membrane (Hybond C; Amersham, Freiburg, Germany). Membranes were blocked in 5\% non-fat dry milk in Tris-buffered saline (TBS) for $1 \mathrm{~h}$ at room temperature and probed with rabbit anti-JNKs antibodies (dilution 1:500; Santa Cruz Biotechnology, Inc.) overnight at $4^{\circ} \mathrm{C}$. After 3 washings with TBS containing $0.1 \%$ Tween-20, membranes were incubated with anti-rabbit IgG horseradish peroxidase (1:5,000; Santa Cruz Biotechnology, Inc.) and developed by luminolmediated chemiluminescence (Appylgen Technologies Inc., China). To confirm equal protein loading, membranes were reprobed with a 1:1,000 dilution of an anti-actin antibody (Santa Cruz Biotechnology, Inc.). Densitometric analyses were performed using Scion Image software.

Soft agar assays. To evaluate the ability of individual cell lines to grow in an anchorage-independent manner, cells were plated in soft agar (Agarose-1000; Gibco-BRL) as previously described (22). In brief, a $2.5 \%$ agarose stock was made in $1 \mathrm{X}$ PBS. The bottom $0.5 \%$ agar support was prepared in DMEM containing $10 \%$ FBS. Cells were harvested, washed and mixed with the top-agarose suspension at a final concentration of $0.3-0.33 \%$, which was then layered onto the bottom agar. The agar plates were incubated at $37^{\circ} \mathrm{C}$ in a humidified incubator for 10 days. Each assay was performed in triplicate. The number of colonies was then counted.

DNA fragmentation assay. Cells were plated in 96-well plates $24 \mathrm{~h}$ before treatment. After treatment, DNA fragmentation was evaluated by examination of cytoplasmic histone-associated DNA fragments (mononucleosomes and oligonucleosomes) using a Cell-Death Detection ELISA kit (Roche Molecular Biochemicals, Indianapolis, IN, USA) according to the manufacturer's recommendations.

Flow cytometry. T98G glioblastoma cells $\left(5 \times 10^{5}\right)$ were seeded in triplicate onto 6-well plates and cultured in RPMI-1640 supplemented with $100 \mathrm{ml} / 1 \mathrm{FBS}$. Following transfection for $48 \mathrm{~h}$, the cells were collected and washed with ice-cold PBS, and fixed in $70 \%$ ethanol overnight at $4^{\circ} \mathrm{C}$. The fixed cells were pelleted, washed in PBS, resuspended in PBS containing $0.1 \mathrm{mg} / \mathrm{ml}$ of propidium iodide and analyzed by flow cytometry.

\section{Results}

The JNKs form one subfamily of the MAPK group of serine/ threonine protein kinases. The JNKs were first identified by their activation in response to a variety of extracellular stresses and their ability to phosphorylate the N-terminal transactivation domain of the transcription factor c-Jun. Our previous studies $(17,23-25)$ revealed that specific inhibition of the JNK pathway in a variety of human tumor cells sensitizes 


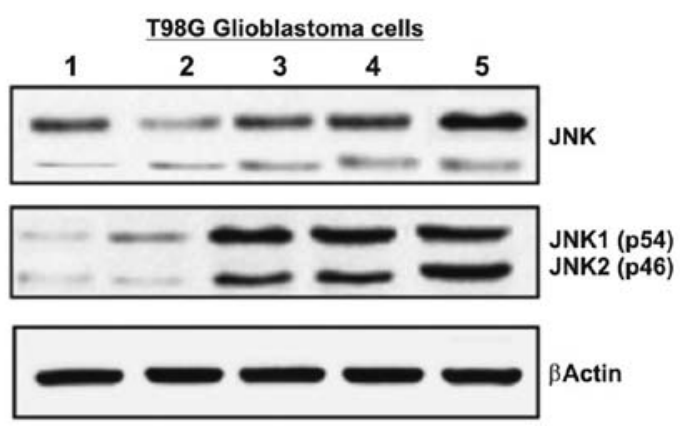

Figure 1. Expression of JNK1 and JNK2 protein levels in T98G glioblastoma cell line in response to several stimuli. T98G cells were treated with FBS $0.5 \%$, FBS $10 \%$, TPA $30 \mathrm{nM}$, and TNF- $\alpha 20 \mathrm{ng} / \mathrm{ml}$. Untreated T98G cells were used as control. $\beta$-actin was used as a loading control. One of three similar experiments is shown. Lane 1, untreated; lane 2, FBS 0.5\%; lane 3, FBS $10 \%$; lane 4, TPA (30 nM); lane 5, TNF- $\alpha(20 \mathrm{ng} / \mathrm{ml})$.

the cells to the cytotoxic effects of cisplatin. In the present study, we characterized the ability of siRNAs against JNK1 and/or JNK2 to induce drug sensitivity in T98G glioblastoma cells. The viability of these cells in the presence of cisplatin was compared to that of the parental and empty-vector control cells.

Expression of JNK1 and JNK2 protein in human T98G glioblastoma cell line. JNK1 and JNK2 are among the nuclear factors that plays an important role in the regulation of several genes. To determine the effect of blocking the expression of both JNK1 and JNK2 by siRNAs, we first studied the protein expression of genes encoding the JNK1 and JNK1 products in T98G cells. The cells were treated with several inductors of JNKs, such as FCS $0.5 \%$, FCS $10 \%$, TPA (30 nM) and TNF- $\alpha$ ( $20 \mathrm{ng} / \mathrm{ml})$. As showed in Fig. 1, the protein expression of JNK1 and JNK2 was assessed by western blot analysis (Fig. 1). The basal protein levels of both JNK1 and JNK2 were higher in the cells cultured in FBS $10 \%$, compared to the cells cultured in FBS $0.5 \%$. Treatment with TPA and TNF- $\alpha$ strongly activated JNK in all cases.

Knockdown of JNK1 and/or JNK2 expression by specific siRNAs strongly decreases the protein levels of JNK gene products and sensitizes cells to the genotoxic effect of cisplatin. In order to study the role of JNKs in the growth regulation of $\mathrm{T} 98 \mathrm{G}$ cells, we treated the cells with specific siRNAs to either JNK1 or JNK2. The cells were then treated with cisplatin at concentrations of $100 \mu \mathrm{M}$ and analyzed for protein expression. The effect of these assays was assessed by western blot analysis (Fig. 2). JNK1/2-siRNAs and to a lower extent cisplatin-treated cells, but not cells treated with scrambled or the untreated cells, showed a marked reduction in protein levels (Fig. 2). The combination of either JNK1siRNA or JNK2-siRNA with cisplatin further increased the genotoxic effect of cisplatin, suggesting that these two proteins appear to be important for $\mathrm{T} 98 \mathrm{G}$ cell survival.

Growth inhibition of T98G cells by siRNAs against JNK1 and JNK2 alone or in combination with cisplatin. Another feature of malignant cells is that they can grow under anchorageindependent conditions. The most common assay to assess

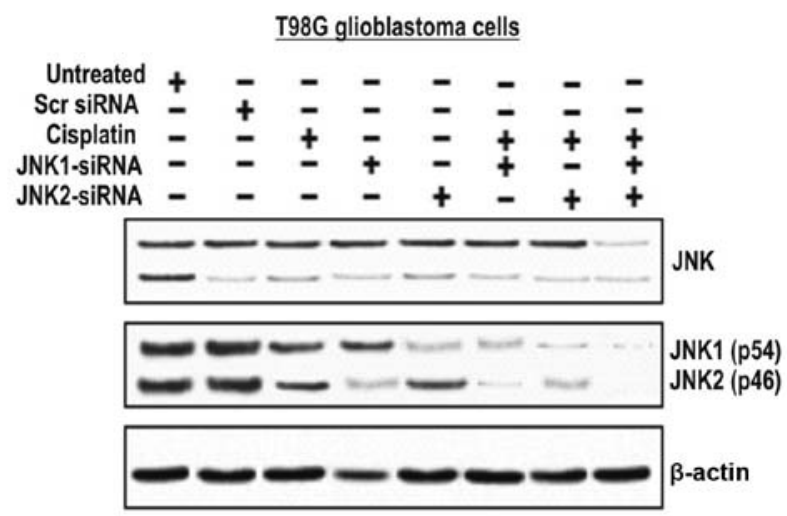

Figure 2. Inhibition of JNK1 and JNK2 protein synthesis by small interfering RNAs and sensitization of T98G cells to cisplatin. T98G glioblastoma cells were transfected with small interfering RNAs (siRNAs) against JNK1 and JNK2 genes, or with scrambled siRNA, in presence or absence of cisplatin $(100 \mu \mathrm{M})$. Western analysis of T98G cells at $24 \mathrm{~h}$ after transfection with siRNAs against JNK1 and JNK2 alone or in combination with cisplatin (cultured for an additional $2 \mathrm{~h}$ ), as shown in Materials and methods. One of three similar experiments is shown.

this is the ability of cells to grow and form colonies in soft agar. As shown in Fig. 3, the untreated T98G cells or cells treated with the scrambled siRNA readily formed colonies in soft agar. In contrast, the T98G cells treated with cisplatin exhibited a greatly reduced capacity to form colonies (Fig. 3). Moreover, the T98G cells treated with siRNA-JNK1 and/or siRNA-JNK2 exhibited a further reduced capacity to form colonies. The combination of cisplatin with siRNAs slightly enhanced the effects obtained with JNK1- or JNK2-siRNA alone. Collectively, these assays clearly demonstrate the ability of the siRNAs against JNK genes to suppress phenotypes related to malignant potential.

Inhibition of JNK1 and JNK2 by siRNAs sensitizes the T98G cells to cisplatin-induced apoptosis. JNKs are activated in response to cytokines or environmental stress and can induce both proapoptotic and pro-survival response (26), we analyzed the role of JNK1 and JNK2 in cisplatin-induced cell apoptosis in glioblastoma cells. Treatment of T98G glioblastoma cells with siRNAs against JNK1 and/or JNK2 decreased IAP activity (Fig. 4A). IAP is a family of proteins involved in preventing cell death by apoptosis. Furthermore, supporting the notion that inhibition of JNK sensitize cells to cisplatin, we treated T98G cells with cisplatin $(100 \mu \mathrm{M})$ or with cisplatin together with cells previously treated with JNK-siRNA or JNK2-siRNA. The activity of IAP proteins was further decreased (Fig. 4A). The two IAP proteins involved in death receptor signaling, cellular inhibitor of apoptosis-1 (cIAP-1) and cIAP-2, undergo rapid cellular elimination after binding to proteins via autoubiquitination and subsequent proteasome-mediated degradation $(27,28)$. In addition, IAPs have been implicated as potential pro-metastatic genes, particularly by promoting cell motility (29). Subsequently, we assessed the effect of JNK knockdown on cisplatin-induced T98G cell death. JNK1 and JNK2 promoted obvious cell survival as shown by decreased DNA fragmentation in the untreated T98G cells (Fig. 4B) and this decrease was strongly attenuated by inhibition of JNK1 and JNK2 using JNK1/2-siRNA transfection. A further increase in DNA fragmentation was observed 


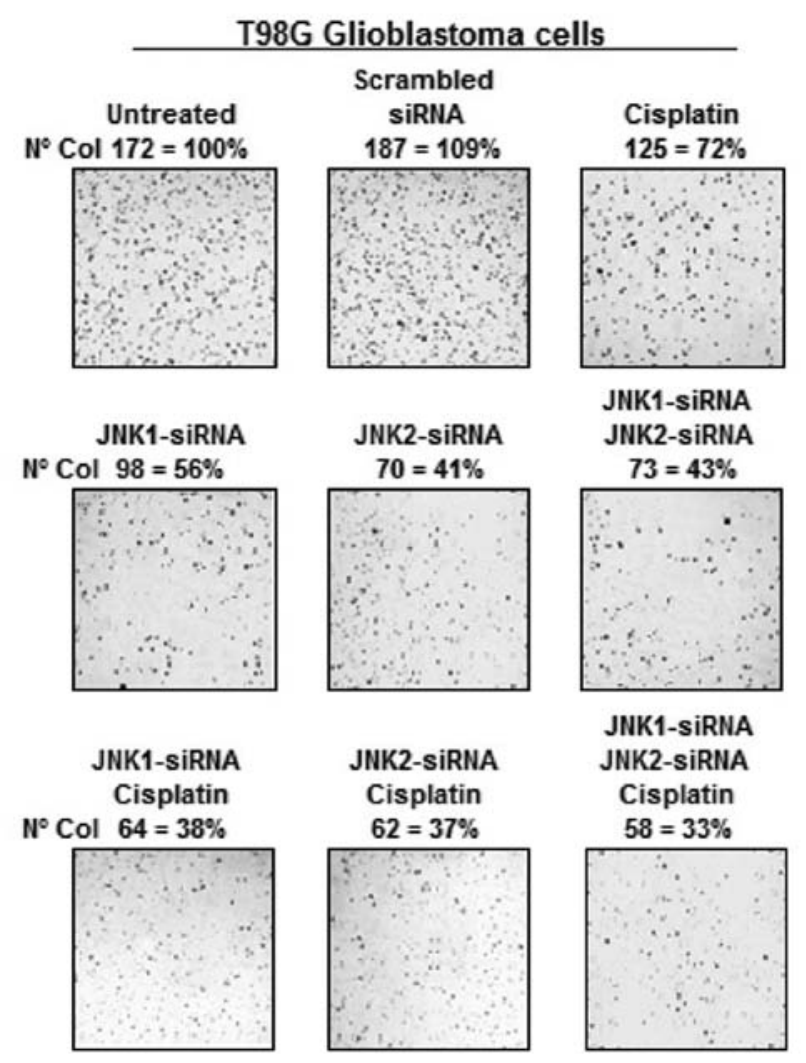

Figure 3. Soft agar assays of cells treated with siRNAs against JNK1 and JNK2, in the presence or absence of cisplatin $(100 \mu \mathrm{M})$, compared with glioma parental cell lines (untreated cells) and those transfected with the scrambled siRNA. T98G cells treated with cisplatin and/or transfected with siRNAs against JNK1 or JNK2 displayed significantly fewer colonies compared with the parental and scrambled siRNA-transfected cells. A further reduction in colony formation was observed when T98G cells were treated with a combination of cisplatin and JNK1-siRNA or JNK2-siRNA. Control and scrambled siRNA caused no inhibition of colony-forming ability of these cells on soft agar. Results are representative of three independent experiments.

in $\mathrm{T} 98 \mathrm{G}$ cells treated with the siRNAs along with cisplatin $(10 \mu \mathrm{M})$, inducing significant apoptosis (Fig. 4B) in the T98G cells. The results suggest a survival role of JNK1 and JNK2 in glioma brain cancer progression.

JNK silencing by siRNAs decreases bcl2 expression, yet strongly induces bax expression, sensitizing the cells to cisplatinmediated apoptosis. Since other pathways may also influence the survival or death of T98G glioblastoma cells, we further analyzed the expression of two genes involved in apoptosis or survival of cells. We investigate the expression of bcl2 and bax gene products in the $\mathrm{T} 98 \mathrm{G}$ cells treated with siRNAs against JNK1 or JNK2 in the presence or absence of cisplatin to investigate the expression of these genes.

The Bcl-2 family proteins regulate a distal step in an evolutionarily conserved pathway for programmed cell death $(30,31)$. Several members of the Bcl-2 protein family can form physical interactions with each other in a complicated network of homodimers and heterodimers (32-34). Although many details remain unclear at present, in general, the ratio between anti-apoptotic proteins such as bcl-2 relative to pro-cell death proteins such as Bax determines the ultimate sensitivity of cells to various apoptotic stimuli (35).

\section{A}

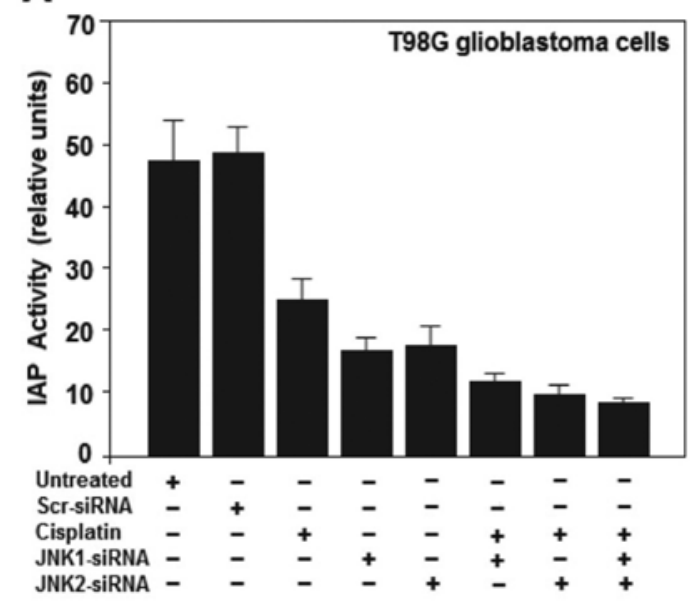

B

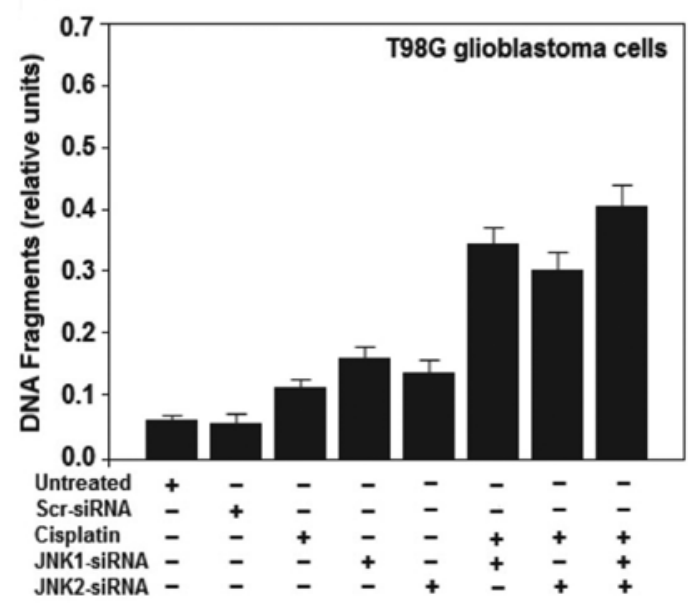

Figure 4. Inhibition of JNK1 and JNK2 by specific siRNAs inhibits cell survival and sensitizes T98G cells to cisplatin. T98G glioblastoma cells were transfected with scrambled siRNA and with siRNAs against JNK1 or JNK-2. Twenty four hours after transfection, cells were treated with cisplatin $(100 \mu \mathrm{M})$ for an additional $2 \mathrm{~h}$. (A) Whole cell proteins were extracted and IAP enzymatic activities in the T98G cells were analyzed. (B) After transfection with JNK1- and JNK2-siRNAs or scrambled siRNA, T98G cells were treated with cisplatin $(100 \mu \mathrm{M})$ for an additional $2 \mathrm{~h}$. Apoptosis was analyzed by determination of DNA fragmentation by an ELISA method. Results are representative of three independent experiments.

As shown in Fig. 5A, the basal levels of the anti-apoptotic gene bcl2, was strongly suppressed in the T98G cells treated with cisplatin. Upon treatment with either JNK1-siRNA or JNK2-siRNA, bcl2 levels decreased to a greater extend. The results also showed a relatively small difference in the regulation of bcl2 gene product by JNK1 and JNK2. Nevertheless, stronger inhibition was reached following treatment with the combination of JNK1-siRNA, JNK2-siRNA and cisplatin (Fig. 5A). As shown in Fig. 5B, the basal level of bax gene expression was altered after treatment of T98G cells with either cisplatin, JNK1-siRNA or JNK2-siRNA. Nevertheless, stronger induction of bax expression was reached in cells treated with a combination of either JNK1-siRNA or JNK2siRNA and cisplatin (Fig. 5B). The effects of cisplatin in both cases (Fig. 5A and B) were substantially increased in the cells previously treated with siRNAs against JNK, clearly indi- 

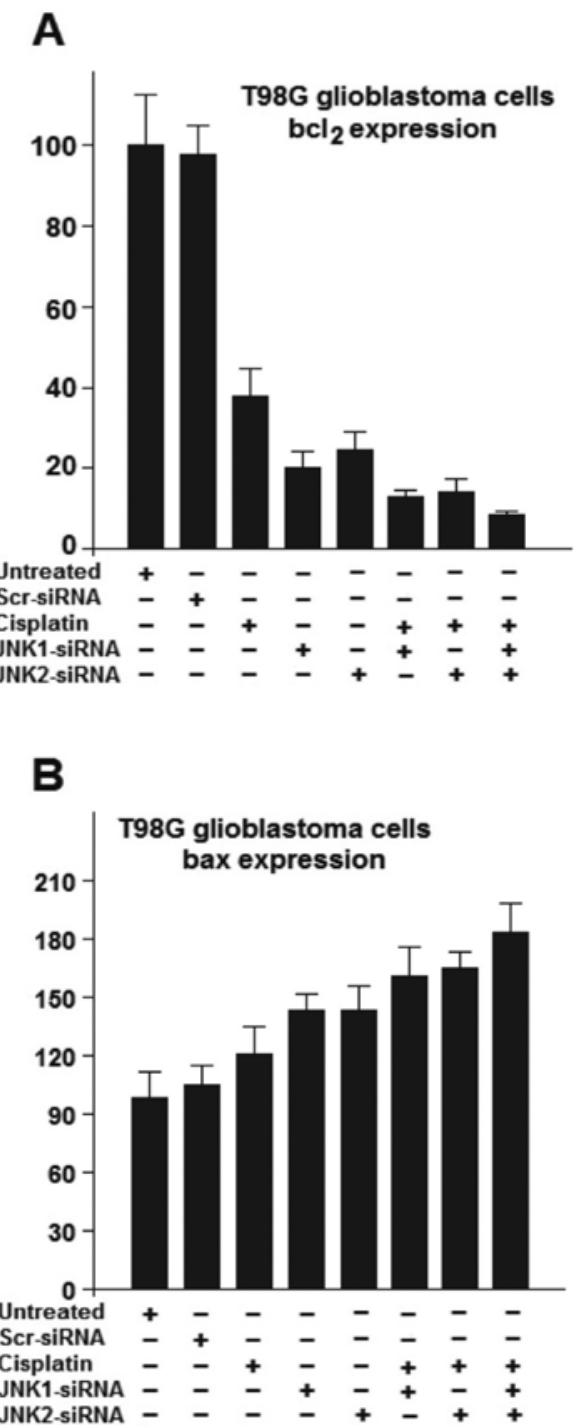

Figure 5. RT-PCR analysis of (A) bcl-2 and (B) bax mRNA levels in T98G glioblastoma cells in response to treatments with scrambled siRNA, cisplatin, JNK1-siRNA and JNK2-siRNA and the combination treatment of cisplatin and JNK1-siRNA or JNK2-siRNA. Levels are represented as the fold change over the untreated controls. Results are representative of three independent experiments.

cating that siRNA against either JNK1 or JNK2 sensitized the T98G cells to cisplatin-mediated apoptosis.

\section{Discussion}

In the present study, we examined how small interfering RNAs (siRNAs) against c-Jun-N-terminal kinase (JNK) affect cell proliferation, DNA repair and susceptibility to apoptosis in T98G glioblastoma cells treated or not with cisplatin. JNK activity is strongly induced in a variety of DNA damaging treatments such as UV irradiation (36), cisplatin (16-19), camptothecin (4) and promotes resistance of tumor cells to cisplatin through a mechanism involving increased DNA repair. Previous studies have shown that a mutant version of c-Jun (mJun), a direct target of the JNK pathway, can inhibit cell proliferation in several types of tumor cells $(37,38)$. In this case, mJun can enter into AP-1 complexes but fails to be activated by JNK due to the alanine replacement at the two critical sites of serine phosphorylation (39). In addition, the effect of blocking JNK pathway expression by siRNA in prostate and breast cancer cells has been demonstrated in several studies $(17,22,24-26)$. In the present study, we examined the role of the JNK pathway following treatment with siRNAs in the presence or absence of cisplatin in T98G glioblastoma cancer cells. We showed that siRNAs against JNKs (siRNAJNK1/2) induced decreased DNA repair and sensitizes the T98G glioblastoma cells to the DNA damaging drug cisplatin. These results were associated with reduced cell survival and loss of anchorage-independent colony formation ability. The results indicate that effective inhibition of the JNK pathway significantly sensitizes glioblastoma cells to cisplatin, a compound of proven clinical value whose spectrum of application is limited by resistance phenomena, further supporting the notion that the JNK pathway may promote survival by limiting genome instability. The loss of p53 in T98G glioblastoma cells would further enhance survival owing to a downregulated apoptotic response. Nevertheless, restoration of p53 in T98G cells through gene transfer results in partial G1 arrest or apoptosis (40). Our results demonstrated that cells treated with JNK-siRNAs exhibit an increased apoptosis and elevated DNA fragmentation compared with untreated T98G cells. Thus, the success or failure of DNA repair in T98G cells may probably play a role in determining the consequences of blocking JNK expression in these tumor cells, suggesting that downregulation of JNK expression could be used to enhance the therapeutic effect of cisplatin in glioblastoma cells. As we have proposed, activation of JNK and loss of p53 may represent independent mechanisms by which tumor cells undergo progression, induce genome instability and ensure survival. By promoting DNA repair, the JNK pathway may help to limit genome instability and the associated DNA damage to levels compatible with survival. This result, combined with inhibition of JNK through siRNAs against JNK1/2, would therefore constitute a tumor-specific therapeutic intervention, since such a strategy exploits the DNA damage resulting from the intrinsic genome instability unique to cancer cells. Such strategies would tend to have synergistic antitumor effects and enhance the potential of DNA damaging chemotherapies as well. Our observations indicate that effective inhibition of the JNK pathway utilizing siRNAs significantly sensitized T98G glioblastoma cells to cisplatin.

\section{Acknowledgements}

This study was supported by the Intramural Regular Research Grant from the Universidad de Tarapacá, UTA-6710-14.

\section{References}

1. Liu Y, Gorospe M, Holbrook NJ and Anderson CW: Posttranslational mechanisms leading to mammalian gene activation in response to genotoxic stress. In: DNA Damage and Repair. Nickoloff JA and Hoekstra MF (eds). Vol 2. Humana Press Inc., Totowa, NJ, pp263-298, 1998.

2. Whitmarsh AJ and Davis RJ: Transcription factor AP-1 regulation by mitogen-activated protein kinase signal transduction pathways. J Mol Med 74: 589-607, 1996.

3. Tournier C, Hess P, Yang DD, Xu J, Turner TK, Nimnual A, Bar-Sagi D, Jones SN, Flavell RA and Davis RJ: Requirement of JNK for stress-induced activation of the cytochrome $c$-mediated death pathway. Science 288: 870-874, 2000. 
4. Parra E and Ferreira J: The effect of siRNA-Egr-1 and camptothecin on growth and chemosensitivity of breast cancer cell lines. Oncol Rep 22: 1159-1165, 2010.

5. Dorigo O, Turla ST, Lebedeva S and Gjerset RA: Sensitization of rat glioblastoma multiforme to cisplatin in vivo following restoration of wild-type p53 function. J Neurosurg 88: 535-540, 1998

6. Ru P, Steele R, Hsueh EC and Ray RB: Anti-miR-203 upregulates SOCS3 expression in breast cancer cells and enhances cisplatin chemosensitivity. Genes Cancer 2: 720-727, 2011.

7. Keshava R, Jothi M, Gope M and Gope R: Functional modulation of the p53 gene and its protein in human brain tumors. Ann Neurosci 15: 3, 2008.

8. Bullock AN and Fersht AR: Rescuing the function of mutant p53. Nat Rev Cancer 1: 68-76, 2001.

9. Raitano AB, Halpern JR, Hambuch TM and Sawyers CL: The $B c r-A b l$ leukemia oncogene activates Jun kinase and requires Jun for transformation. Proc Natl Acad Sci USA 92: 11746-11750, 1995.

10. Dickens M, Rogers JS, Cavanagh J, Raitano A, Xia Z, Halpern JR, Greenberg ME, Sawyers CL and Davis RJ: A cytoplasmic inhibitor of the JNK signal transduction pathway. Science 277: 693-696, 1997.

11. Shi CS, Tuscano JM, Witte ON and Kehrl JH: GCKR links the $B c r-A b l$ oncogene and Ras to the stress-activated protein kinase pathway. Blood 93: 1338-1345, 1999.

12. Atfi A, Prunier C, Mazars A, Défachelles AS, Cayre Y, Gespach $C$ and Bourgeade MF: The oncogenic TEL/PDGFR $\beta$ fusion protein induces cell death through JNK/SAPK pathway. Oncogene 18: 3878-3885, 1999

13. Bost F, McKay R, Dean N and Mercola D: The JUN kinase/stressactivated protein kinase pathway is required for epidermal growth factor stimulation of growth of human A549 lung carcinoma cells. J Biol Chem 272: 33422-33429, 1997.

14. Nielsen C, Thastrup J, Bøttzauw T, Jäättelä $\mathrm{M}$ and Kallunki T: c-Jun $\mathrm{NH}_{2}$-terminal kinase 2 is required for Ras transformation independently of activator protein 1. Cancer Res 67: 178-185, 2007.

15. Wu S, Loke HN and Rehemtulla A: Ultraviolet radiation-induced apoptosis is mediated by Daxx. Neoplasia 4: 486-492, 2002.

16. Mansouri A, Ridgway LD, Korapati AL, Zhang Q, Tian L, Wang Y, Siddik ZH, Mills GB and Claret FX: Sustained activation of JNK/p38 MAPK pathways in response to cisplatin leads to Fas ligand induction and cell death in ovarian carcinoma cells. J Biol Chem 278: 19245-19256, 2003.

17. Parra E and Ferreira J: Modulation of the response of prostate cancer cell lines to cisplatin treatment using small interfering RNA. Oncol Rep 30: 1936-1942, 2013.

18. Persons DL, Yazlovitskaya EY, Cui W and Pelling JC: Cisplatininduced activation of mitogen-activated protein kinases in ovarian carcinoma cells: inhibition of extracellular signalregulated kinase activity increases sensitivity to cisplatin. Clin Cancer Res 5: 1007-1014, 1999.

19. Sánchez-Perez I, Murguía JR and Perona R: Cisplatin induces a persistent activation of $\mathrm{JNK}$ that is related to cell death Oncogene 16: 533-540, 1998

20. Costa-Pereira AP, McKenna SL and Cotter TG: Activation of SAPK/JNK by camptothecin sensitizes androgen-independent prostate cancer cells to Fas-induced apoptosis. Br J Cancer 82 : $1827-1834,2000$

21. Woo RA, McLure KG, Lees-Miller SP, Rancourt DE and Lee PW: DNA-dependent protein kinase acts upstream of p53 in response to DNA damage. Nature 394: 700-704, 1998.
22. Still IH, Hamilton M, Vince P, Wolfman A and Cowell JK: Cloning of TACC1, an embryonically expressed, potentially transforming coiled coil containing gene, from the 8 p11 breast cancer amplicon. Oncogene 18: 4032-4038, 1999.

23. Parra E, Gutiérrez L and Ferreira J: Increased expression of p21Waf1/Cip1 and JNK with costimulation of prostate cancer cell activation by an siRNA Egr-1 inhibitor. Oncol Rep 30: 911-916, 2013.

24. Parra E: Inhibition of JNK-1 by small interfering RNA induces apoptotic signaling in PC-3 prostate cancer cells. Int J Mol Med 30: 923-930, 2012

25. Parra E and Ferreira J: Knockdown of the c-Jun-N-terminal kinase expression by siRNA inhibits MCF-7 breast carcinoma cell line growth. Oncol Rep 24: 1339-1345, 2010

26. Weston CR and Davis RJ: The JNK signal transduction pathway. Curr Opin Cell Biol 19: 142-149, 2007.

27. Vucic D, Dixit VM and Wertz IE: Ubiquitylation in apoptosis: a post-translational modification at the edge of life and death. Nat Rev Mol Cell Biol 12: 439-452, 2011.

28. Bertrand MJ, Milutinovic S, Dickson KM, Ho WC, Boudreault A, Durkin J, Gillard JW, Jaquith JB, Morris SJ and Barker PA: cIAP1 and cIAP2 facilitate cancer cell survival by functioning as E3 ligases that promote RIP1 ubiquitination. Mol Cell 30: 689-700, 2008

29. Fulda S: Regulation of cell migration, invasion and metastasis by IAP proteins and their antagonists. Oncogene 33: 671-676, 2014

30. Gascoyne RD, Krajewska M, Krajewski S, Connors JM and Reed JC: Prognostic significance of Bax protein expression in diffuse aggressive non-Hodgkin's lymphoma. Blood 90: 3173-3178, 1997.

31. Youle RJ and Strasser A: The BCL-2 protein family: opposing activities that mediate cell death. Nat Rev Mol Cell Biol 9: 47-59, 2008.

32. Zha H, Aimé-Sempé C, Sato T and Reed JC: Proapoptotic protein $\mathrm{Bax}$ heterodimerizes with $\mathrm{Bcl}-2$ and homodimerizes with Bax via a novel domain (BH3) distinct from $\mathrm{BH} 1$ and $\mathrm{BH} 2 . \mathrm{J}$ Biol Chem 271: 7440-7444, 1996.

33. Reed JC: Mechanisms of Bcl-2 family protein function and dysfunction in health and disease. Behring Inst Mitt 97: 72-100, 1996.

34. Metcalfe AD, Gilmore A, Klinowska T, Oliver J, Valentijn AJ, Brown R, Ross A, MacGregor G, Hickman JA and Streuli CH: Developmental regulation of $\mathrm{Bcl}-2$ family protein expression in the involuting mammary gland. J Cell Sci 112: 1771-1783, 1999.

35. Basu A and Haldar S: The relationship between Bcl2, Bax and p53: consequences for cell cycle progression and cell death. Mol Hum Reprod 4: 1099-1109, 1998.

36. Fritz $\mathrm{G}$ and Kaina B: Activation of c-Jun N-terminal kinase 1 by UV irradiation is inhibited by wortmannin without affecting c-jun expression. Mol Cell Biol 19: 1768-1774, 1999.

37. Smeal T, Binetruy B, Mercola DA, Birrer M and Karin M: Oncogenic and transcriptional cooperation with Ha-Ras requires phosphorylation and $c$-Jun on serines 63 and 73. Nature 354: 494-496, 1991

38. Brown PH, Chen TK and Birrer MJ: Mechanism of action of a dominant-negative mutant of c-Jun. Oncogene 9: 791-799, 1994.

39. Shaulian E and Karin M: AP-1 in cell proliferation and survival. Oncogene 20: 2390-2400, 2001.

40. Huang LC, Clarkin KC and Wahl GM: Sensitivity and selectivity of the DNA damage sensor responsible for activating p53-dependent $G_{1}$ arrest. Proc Natl Acad Sci USA 93: 4827-4832, 1996. 